ANNALS, $A A P S S, 464$, November 1982

\title{
Blacks at Middle and Late Life: Resources and Coping
}

\author{
By ROSE C. GIBSON
}

\begin{abstract}
An analysis of national data collected in 1957 and 1976 reveals that older black Americans' use of their informal support networks and prayer in times of distress is distinct from that of older white Americans. Black-white disparities in income, education, and widowhood were large and appeared to widen from middle to late life. Blacks, in coping with distress, drew from a more varied pool of informal helpers than whites, both in middle and late life, and were more versatile in substituting these helpers one for another as they approached old age. Whites, in contrast, were more likely to limit help seeking to spouses in middle life and to replace spouses with a single family member as they approached old age. Blacks were much more likely than whites to respond to worries with prayer, but prayer, as a coping reaction among blacks, declined between 1957 and 1976. The role of the special help-seeking model of older blacks in their adaptation to old age is discussed.
\end{abstract}

Rose C. Gibson is a research scientist at the University of Michigan's Institute of Gerontology. She has been a United States Public Health Service Fellow and has been engaged in extensive research on aging and aged black women. 
$\mathrm{T}$ HERE is a distance between blacks and whites in their middle years. Black Americans are poorer, less educated, more apt to be separated, divorced, or widowed. And the gap widens with age. At midlife, census figures show that 14 percent of blacks have family incomes of less than $\$ 5000$, compared with 4 percent of whites; 64 percent of blacks have educational attainments of less than high school graduation, compared with 34 percent of whites; and 55 percent of midlife blacks are married with spouse present, compared with 79 percent of whites. For the elderly, census figures show that 27 percent of blacks have family incomes of less than $\$ 5000 ; 80$ percent have less than a high school education; and only 38 percent are married and make a home with their spouse. The comparable figures for older whites are 10 percent, 34 percent, and 54 percent, respectively. (See Table 1 and Figure 1.)

Even though they lack financial security, education, and marital harmony-aspects of life assumed to ease one's way-blacks seem to sustain themselves psychologically as they age. ${ }^{1}$ Certainly in terms of a gross measure of adjustmentsuicide-older blacks fare we National vital statistics indicate suicide rates among the elderly, from lowest to highest, are those of black females, black males, white

1. See Joseph Veroff, Elizabeth Douvan, and Richard Kulka. The Inner American: $A$ Self-Portrait from 1957 to 1976 (New York: Basic Books, 1981), p. 436; Inabel B. Lindsay, "Coping Capacities of the Black Aged," in No Longer Young: The Older Woman in America, Occasional Papers in Gerontology, no. 11 (Ann Arbor: Institute of Gerontology, University of Michigan), pp. 89-94; Rose C. Gibson, "The Survivors: Black Elderly 75 Years Old and Over," (Manuscript in preparation. Institute of Gerontology, University of Michigan, 1982). females, and white males. ${ }^{2}$ This rank ordering corresponds directly to the likelihood of being poor. That is, older black women are most likely to be poor and least likely to end their own lives; older white men are least likely to suffer poverty and most apt to die by their own hand.

So what accounts for the staying power of American blacks? Is it merely a matter of practice, of long experience in meeting adversity? Or have they found resources and strategies that sustain them? This article examines two specific coping practices-prayer and seeking help from family and friends - to which black Americans reportedly resort when times are difficult. ${ }^{3}$ Black people in middle and late life turn to prayer more often than do white people of similar years. Blacks use their informal networks differently from whites, and the patterns of prayer and network use are changing. The adaptive values of these two strategies, then, may make blacks' entry into old age more transition than crisis.

\section{METHOD}

The data examined here are from the $1957 / 1976$ study, Americans View Their Mental Health. ${ }^{4}$ This major national study is based on a

2. National Center for Health Statistics, Vital Statistics of the United States, 1975 (Washington, DC: Government Printing Office).

3. U.S. Senate Special Committee on Aging, "The Multiple Hazards of Age and Race: The Situation of Aged Blacks in the United States" (Washington, DC: Government Printing Office, 1971); see, for example, Joseph Dancy, Jr., "Religiosity and SocialPsychological Adjustment Among the Black Urban Elderly," Ph.D. dissertation, University of Michigan, 1979); James S. Jackson, Report to Respondents, The National Survey of Black Americans (Ann Arbor: Institute for Social Research, University of Michigan, 1982).

4. Gerald Gurin, Joseph Veroff, and Sheila Feld, Americans View Their Mental 
TABLE 1

TOTAL INCOME, EDUCATIONAL ATTAINMENT, AND MARITAL STATUS

OF BLACKS AND WHITES AT MID- (AGES 45-64) AND LATE-LIFE (AGES 65 AND OVER)

\begin{tabular}{ccc} 
MID-LIFE & LATE-LIFE \\
BLACK WHITE & BLACK WHITE \\
\hline
\end{tabular}

Total income of families by race of

Household head, 1979 (in percentages)*

Less than $\$ 5000$ a year

Total number

Educational at tainment of persons,

1979 In (in percentages) †

Less than high school graduate

Total number

Marital status of persons, 1978

(in percentages) $\neq$

Single

Married, spouse present

Married, spouse absent

Widowed

Divorced

Total number

$\begin{array}{rrrr}14 & 4 & 27 & 10 \\ 1772 & 17921 & 789 & 7911\end{array}$

64

34

80

34

$4054 \quad 38737$

1677

23505

911

* U.S. Bureau of the Census, "Money Income of Families and Persons in the United States," Current Population Reports, Series P-60, No. 129 (Washington, DC: Government Printing Office, Nov. 1981), Table 21, pp. 87-88, 91-92.

† U.S. Bureau of the Census, "Educational Attainment in the U.S., March 1979 and 1978," Current Population Reports, Series P-20, No. 356 (Washington, DC: Government Printing Office, Aug. 1980), Table 1.

\# U.S. Bureau of the Census, "Marital Status and Living Arrangements," Current Population Reports, Series P-20, No. 333 (Washington, DC: Government Printing Office, May 1979), Table 1, pp. 8-9.

probability sample of the adult black and white population. The present study analyzes data on blacks and whites who were in their middle years (ages 45 to 59) and late years (ages 60 and older) in 1957, and blacks and whites who had attained similar ages in 1976 . The 1957 sample is composed of 50 middle-aged and 32 older blacks, and 566 middle-aged and 455 older whites. The 1976 figures are 46,55 , 447 , and 493 , respectively. The

Health (Institute for Social Research, University of Michigan) (Ann Arbor: ISR Social Science Archive, Institute for Social Research, 1957, 1976). black samples in both years were poorer, less educated, and less apt to be married than the white samples.

To assess use of the informal network and use of prayer as coping responses to distress, and to determine the persistence of these strategies from 1957 to 1976 , respondents in both years were asked how they handled matters that were bothering or worrying them. They were also asked if they talked the problem over with anyone and, if so, with whom. The responses given fell into eight categories: informal help seeking, religious means (prayer being primary among such means), 
FIGURE 1

DIFFERENCES IN TOTAL INCOME, EDUCATIONAL ATTAINMENT, AND MARITAL STATUS OF BLACKS AND WHITES AT MID-(AGES 45 TO 64* YEARS) AND LATE-LIFE (AGES 65 YEARS AND OVER

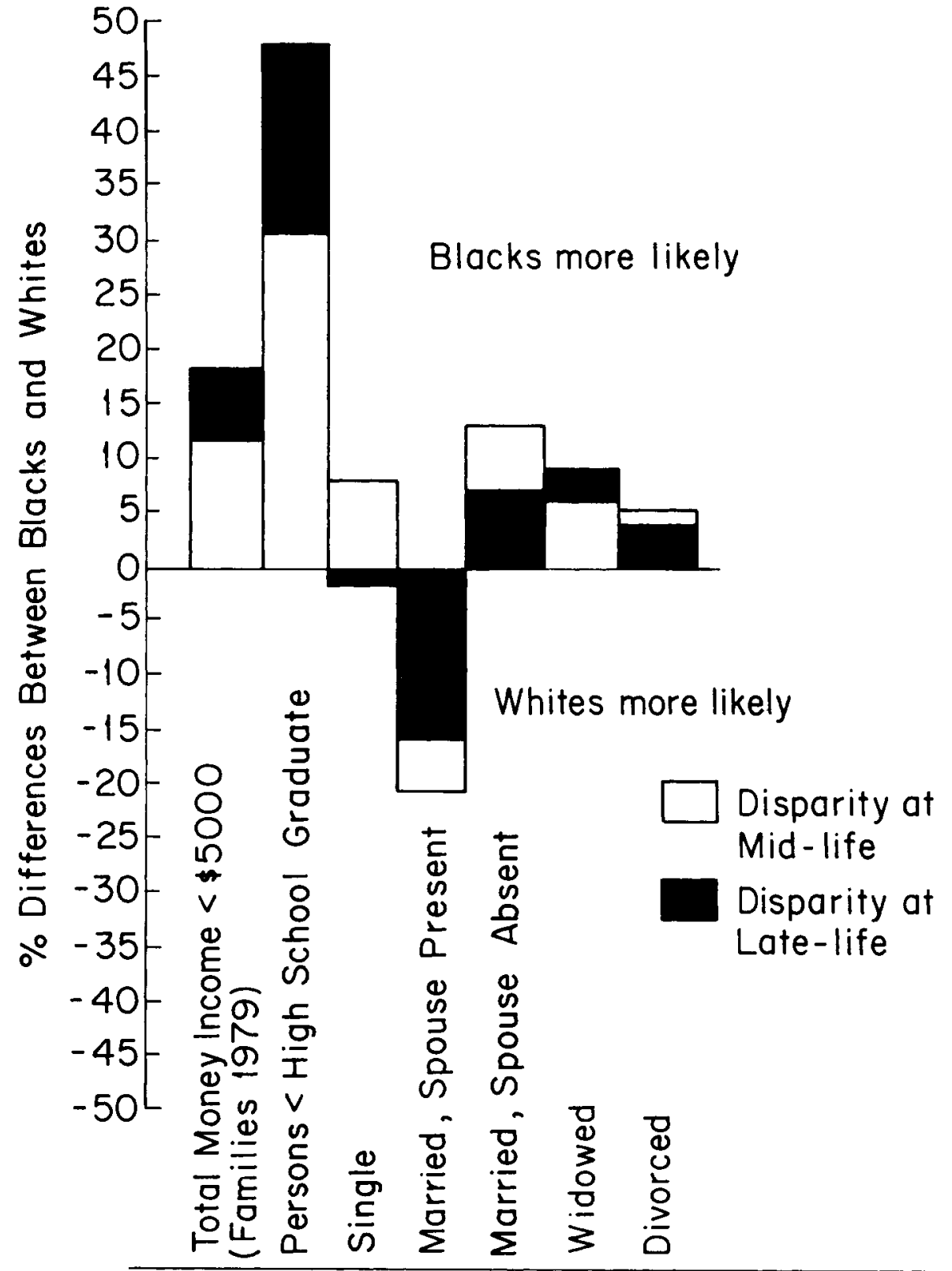

*Table 1 of this article. 
denial, displacement, passive reactions, independent coping reactions, and "other" (this category included such reactions as sleep, drink, fantasy, and medication). These categories are listed in Table 2 .

To determine racial and generational differences in patterns of help seeking within the informal network, those mentioned receiving informal help were placed into four additional categories: "spouse only"-respondent named a spouse and no one else; "single family member"-respondent named only a family member other than a spouse; "multiple family members"-respondent named two or more family members; and "friends"-respondent named friends, acquaintances, or neighbors (see Table 3 ).

\section{SEEKING HELP IN \\ THE INFORMAL NETWORK}

Whites in the Americans View Their Mental Health samples made greater overall use of the informal network at times of worry, both in 1957 and 1976, although older blacks and older whites were about equally likely to do so in 1976, as Table 2 indicates. The greater use of informal network members by whites was mainly because whites were much more likely than blacks, in both years and at both life stages, to seek help exclusively from their spouses (see Table 3). Whites were also more likely in each analysis year to seek help from one family member at a time. Blacks, on the other hand, were more likely than whites to seek help from friends in 1957 and from combinations of family members in 1976 . Controlling for marital status, whites were still much more likely than blacks to discuss their worries with spouses exclusively. Similarly, racial differences in single family member and multiple family member use within the informal network remained, after income, education, number of adults living in the respondents' household, and age were held constant. ${ }^{5}$

In sum, middle and late life blacks, in both 1957 and 1976, were less likely than their white counterparts to seek help in the informal network only from a spouse or from one family member. The model of reaching beyond single family members in times of need is evident among blacks in both years. ${ }^{6}$

Also evident in both years is that blacks select from a more varied pool of helpers as aging takes place; they substitute one type of helper for another. Blacks who were middle aged in 1957 seem to have shifted by 1976 , when they were elderly, from use of friends in times of worry to use of multiple family members. In contrast, the whites who were middle aged in 1957 seem to have continued reliance only on spouses when possible and to hvae increased their use of single family members, presumably as a replacement for lost

5 . We were unable, because of small numbers of blacks in the upper income and education categories, to apply adequate controls for these two variables. We instead analyzed racial differences within the lower income and education groups. It is unknown, then, whether higher-status groups, with respect to income and education, behave similarly.

6. Recognizing this help-seeking pattern of reaching beyond single family members as characteristic of women, and realizing that there were proportionately more older black women than older black men in our sample, we analyzed the sex data separately to determine whether these were actually sex, and not race, differences in use of the informal network. The numbers of black men in some of the age categories were too small for definitive statements, but black men seemed as 


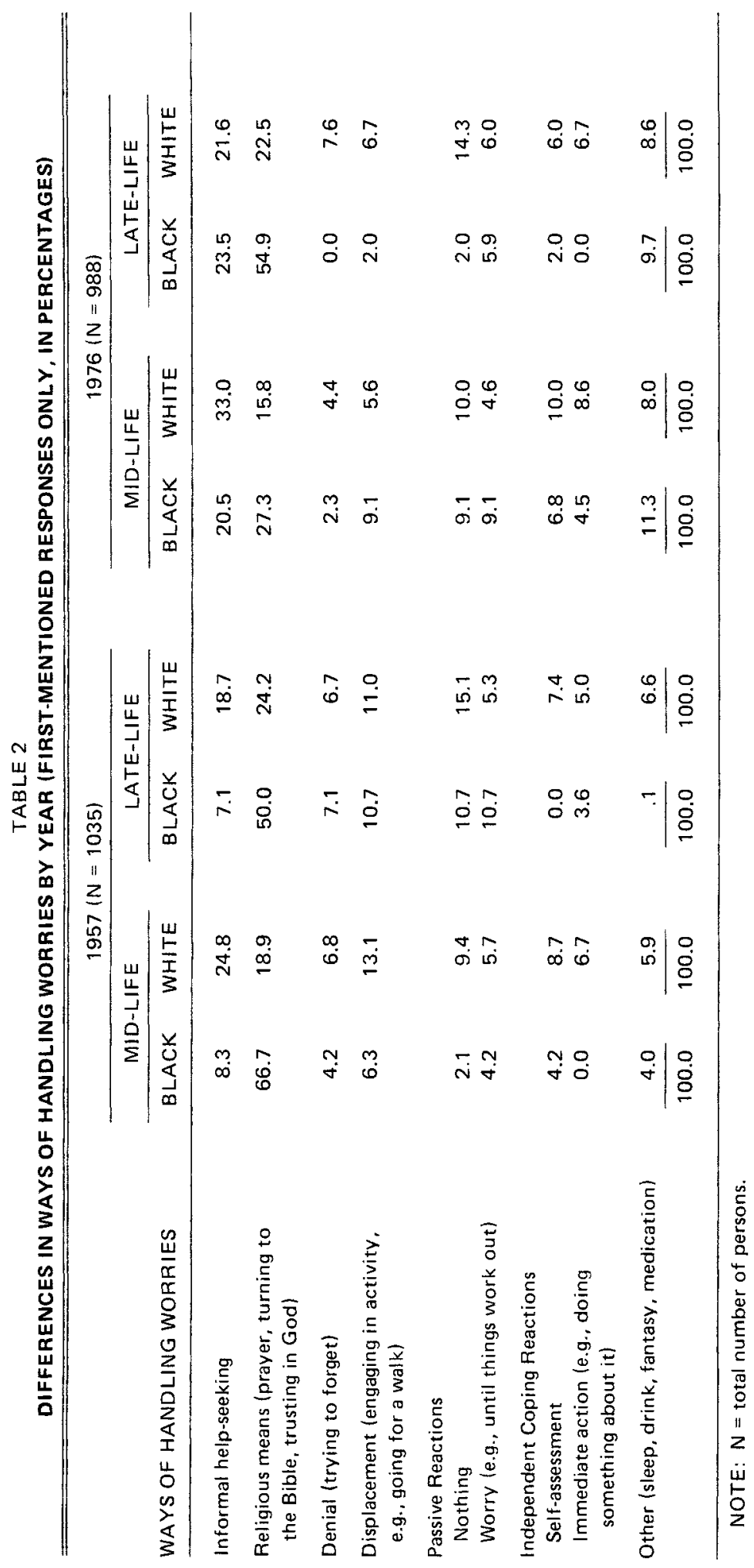




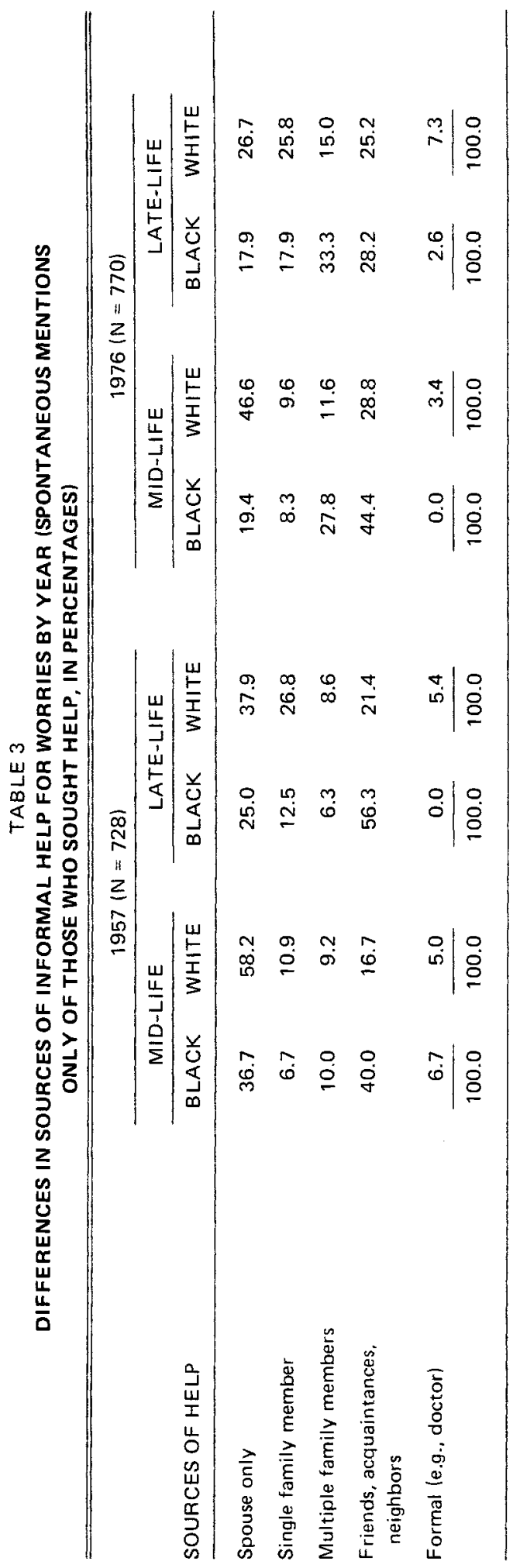


spouses. They also increased their use of multiple family members, but not nearly so much as did their black counterparts.

The use of multiple family members for help with worries seems to increase as blacks move from middle to old age. Only onetenth of the midlife blacks sought help from multiple family sources in 1957, while one-third of the latelife blacks did so in 1976 (see Table 3 ). The latter apparently increased the use of combinations of family members as they aged. Turning to various family members in times of need appears to be a growing phenomenon, particularly among elderly blacks; the increase in this pattern of help seeking was greater for this group between 1957 and 1976 than for any other race or age group.

In short, similarities in both analysis years suggest that a paradigm of seeking help beyond the narrowest range of helpers, and of increasing versatility in the substitution of types of helper as aging occurs and life circumstances and needs change, may be characteristic of blacks when they attempt to cope with worries.

\section{PRAYER AS COPING}

In line with conventional wisdom, black respondents in this study were much more likely than their white counterparts to react to worry with prayer. This holds true for the mid- and late-life samples in both 1957 and 1976. Prayer, in fact, remained the modal response of blacks in each of these years, suggesting that recourse to prayer may well have been one of blacks' tradi-

likely as their black women counterparts to seek help from combinations of family members rather than from single family sources. tional means of handling worries. Racial differences in the use of prayer remained when education and income were held constant.

The cohort of blacks who were middle aged in 1957 may represent a generation of blacks who regularly found relief from worry through prayer. A majority of this cohort turned to prayer in 1957 (two-thirds of the midlife cohort) and a majority did so in 1976 (55 percent of the late-life cohort). Presumably, this generation continued to find solace in prayer as they aged.

In spite of the fact that this group continued to use prayer as a means of handling worry, prayer became a less prominent source of relief to them as they aged. The decrease in the proportion who used prayer (from two-thirds in 1957 to 55 percent in 1976) may mean that, even among blacks who learned to respond to worry with prayer, prayer as a means of coping may be on the decline. ${ }^{7} \mathrm{~A}$ further indication that prayer may be on the decline among blacks is that midlife blacks in 1976 were much less inclined than midlife blacks in 1957 to use prayer.

An interesting note is that suicide rates among the black and white elderly not only mirror income levels, as mentioned earlier, but also the likelihood of responding to worry with prayer. That is, elderly black women are least likely to commit suicide and most likely to use prayer as a coping response. Elderly white men are most inclined toward suicide and least inclined toward prayer. Elderly black men and elderly white women

7. Prayer as a response to worries is also decreasing among all Americans. Joseph Veroff, Elizabeth Douvan, and Richard Kulka, The Inner American: A Self-Portrait from 1957 to 1976 (New York: Basic Books, 1981), p. 483. 
are ordered between these extremes.

This association between lower suicide rates and praying in times of need may be simply an interesting coincidence. Durkheim, however, suggests the incidence of suicide is lowest among those who are most strongly bonded to groups-the greater the degree of social integration, the less the tendency toward suicide. ${ }^{8}$ And many authors have noted that blacks frequently pray together in times of need. ${ }^{9}$ It may well be this communal aspect of prayer, the sense of prayer as a source of social support, that provides the logical link between prayer and lower suicide rates among older blacks.

Furthermore, Durkheim offers evidence that the greater the number of elements in a family grouping, the lower the incidence of suicide. As we observed earlier, older blacks tend to define their family groups broadly when seeking help; support may come from a number of family members. Older whites, on the other hand, limited their help seeking more to single family members. These findings suggest that blacks may be more and whites less bonded to groups of

8. Durkheim explains further the role of family density in suicide, "The functioning of the family varies with its greater or lesser density, the number of its component elements affects the suicidal tendency. Where collective sentiments are strong, it is because the force with which they affect each individual conscience is echoed in all the others, and reciprocally. The intensity they attain therefore depends on the number of consciences which react to them in common." Emile Durkheim, Suicide, A Study in Sociology (New York: Free Press, 1951), pp. 201, 209.

9. See James T. Widgeon, "Differences in the Meaning of Religion for Blacks and Whites: Racial Differences on Indicators of Religiosity" (Unpublished manuscript, University of Michigan, Institute for Social Research, 1981). helpers. It is possible that this greater and lesser bonding by blacks and whites, respectively, to multiple sources of help is related to their respective suicide rates. If lower suicide rates do indeed reflect better adjustment in old age, the bonding theory, though speculative, may explain more fully the role of the use of combinations of family members in the better adjustment of blacks to old age.

In sum, blacks were much more likely than whites at both middle and late life to respond to worry with prayer. This type of response is likely to have been a characteristic of blacks in the past, but it may now be on the decline as a coping strategy, even among the black elderly. The use of combinations of family members in response to worry, furthermore, seems to be increasing among older blacks as the use of prayer is decreasing. One may wonder whether multiple help seeking in the informal network will eventually replace prayer as the dominant mode of handling distress.

\section{SUMMARY AND CONCLUSION}

The blacks in our sample were poorer, less educated, and more likely to have experienced family disruption than the whites at both middle and late life and in both 1957 and 1976. If we assume that money, education, and nuclear family harmony serve to moderate stress, then blacks approach middle and late life less fortified against stress than whites.

Blacks were less likely than whites to rely upon single sources of family help in times of worry; in addition, blacks from middle to late life exhibited greater virtuosity 
than whites in substituting one type of informal helper for another, still within a paradigm of not limiting help seeking to single family members. This pattern among blacks of seeking help from a broader base of helpers increased with age.

Evident in both 1957 and 1976 were the tendencies of blacks to reach beyond single sources of support in the family and to interchange one informal helper for another, suggesting that these tendencies may represent longstanding patterns blacks have followed when coping with worries. From the present cross-sectional data, we cannot be sure that this is so. It is possible, however, that blacks, as they age, compensate for the diminution of other resources in a unique fashion-by increasing the variety of informal helpers from whom they may usefully seek help at critical transitional stages.

The data we examined showed that blacks, much more than whites, at both middle and late life turned to prayer as a response to worry. It appears, however, that prayer as a coping reaction to worry is on the decline among elderly blacks and even seems to decrease as they age. Blacks seeking help with their worries seem to be increasing the use of combinations of family members and decreasing the use of prayer.

In what ways might these unique strategies of older blacks, to call upon combinations of family members and to substitute one informal helper for another, promote greater adaptation to old age than is the case among whites? First, blacks may be more socialized to seeking help from combinations of family members and to substituting one type of informal helper for another. This help seek- ing from a wider base and flexibility in substitution may even have been sensitive to changing circumstances and changing needs over life course, thereby helping blacks through critical stages.

Next, this greater socialization of blacks to use of a multiple-help paradigm with an overlay of flexibility might mean that as close family and friends are lost, they are more easily replaced by others from within the informal network. For example, blacks, having learned to draw from a larger pool of helpers, may be more likely in late life to have these helpers in place; and having rehearsed multiple use of family members and substitution of these helpers at critical life points, they may also be more likely to have welloiled machinery in place to facilitate this selection and substitution of helpers. Having both helpers and the mechanisms in place may ease the transition of blacks into old age. Analogously, older whites, because they limited help seeking to single family sources and had little rehearsal in substituting a variety of informal helpers, may have more difficulty in replacing these single sources of help as they are lost. Thus the move into old age is less tranquil for whites than it is for blacks.

Finally, the multidimensionality of help received from informal network helpers may be an important consideration in the psychological survivorship of older blacks. For example, the help received from friends or combinations of family members may be different in quantity, type, or quality from the help received from a spouse or a single family member. If this assumption is true, than the quantity, type, or quality of help can be changed by changing the helpers. This method would be a benefit in coping with 
changing needs brought about by aging.

The decline of prayer suggests that it will not be the dominant coping strategy of elderly blacks in the future. Why is prayer as a coping reaction to worry decreasing among older blacks? First, resorting to prayer as a means of coping with problems may be inversely related to the size of the opportunity structure for blacks. As opportunities widen for blacks (as for example, they did between 1957 and 1976), more avenues to problem solving open, providing options other than prayer for use in solving problemssuch as direct actions. This greater access to other modes of coping means that older blacks are better able to negotiate their environments and their family members are better able to arrange their environments as well-creating for older blacks less need to turn to powerful others for help and at the same time placing black family members in better positions to help their older family members. In other words, older blacks, their kin, and friends are more able to handle their problems directly. Extending the theory further, if positive outcomes are more often associated with direct actions than with prayer, these alternate strategies would become more rewarding and more motivating than prayer, and thus prayer as a means of coping with problems would begin to decline. An alternate explanation, of course, is that yesterday's prayers are being answered in today's empowerment and that older blacks' need for supplication has become less urgent and less global. If opportunities continue to widen for blacks and their family members, prayer as a coping strategy may eventually be replaced by help seeking in the informal net- work. The present data suggest that this decline has already begun; that is, use of combinations of family members was observed to increase as the use of prayer decreased from 1957 to 1976.

We might argue, then, that lifetime rehearsal in using combinations of family members and friends; flexibility in interchanging these helpers at critical life points; and being able to manipulate the level, quantity, and type of help available by manipulating the helpers-coupled with the fact that blacks may also be more socialized to adapt to uncertainty and change within their lives-make up a dynamic coping package that is sensitive to life's changing circumstances and changing needs. This coping package, used at successive transitions, may become increasingly polished; those blacks who learn to use the package most effectively at previous stages overcome roadblocks more successfully at successive stages. These survivors thus arrive at the penultimate transition-old age-more fortified, more rehearsed, and better able to adapt to its exigencies, despite fewer economic and social resources. For blacks, then, the move into old age may be more transition than crisis. The critical issue of whether the strategies contained in this coping package are correlated with psychological survivorship remains open to question.

If the coping armamentarium of blacks is indeed different from that of whites and if it is this difference that accounts for the purported greater adaptation of blacks to old age, there needs to be a more precise analysis of the factors that constitute this coping package: its elements, the proportions of these elements that yield maximum effectiveness in coping, and its ability to 
change in response to life changes. If old age does indeed inherit what has gone before, is the ease with which individuals make the transition into old age predictable from the successful use of this package earlier in life? More importantly, are these adaptive strategies teachable?

If blacks have truly developed and used extraordinary coping repertoires that sustain them psychologically in old age, the mistake must not be made of thinking that this psychological well-being is an adequate substitute for economic and social well-being in old age. The goal of social policy, in fact, must be to strike a balance among the economic, social, and psychological components of well-being by attempting to equalize these factors in the lives of the black and white elderly. This equalization could be effected by strengthening the weaknesses of each group. If the adaptive strategies of blacks in old age are superior to those of whites, then the adaptive mechanisms of whites might be altered based on what is known about the successful strategies employed by blacks. Similarly, the economic and social resources of older blacks must be increased to levels that approach those of comparable whites. Such a balance would help to insure that the move into old age for blacks and whites alike will be more transition than crisis. 